\title{
Interactions between the limpet Patelloida latistrigata and algae on an intertidal rock platform
}

\author{
P. Jernakoff ${ }^{*}$ \\ Department of Zoology, AO8, University of Sydney, NSW 2006, Australia
}

\begin{abstract}
The small acmaeid limpet Patelloida latistrigata Angas and clumps of macroalgae are found in midshore intertidal regions dominated by barnacles. Interactions between limpet and algae were investigated experimentally to determine the effect of the herbivore on microalgae (this term includes propagules of macroalgae) as well as on macroalgal plants, and also the influence of both forms of algae on the behaviour of the limpet. P. latistrigata grazed on propagules of all algae, even species previously reported to be unaffected by grazing. The high diversity of algae in ungrazed areas was due to the abundance of microscopic propagules. Although limpets survived on macroalgae they tended to migrate to bare rock and grazed on microalgae. Large germlings of ephemeral algae were not efficiently digested but could support limpet survival. Although $P$. latistrigata is a generalist grazer of microalgae, experiments reveal that its microalgal grazing is not obligatory.
\end{abstract}

\section{INTRODUCTION}

The consequences of being obligate grazers of microalgae are becoming clear for herbivorous gastropods on rocky shores of southeastern Australia; dominance by algae or limpets depends on the rate of algal growth and the grazing rate of gastropods (Underwood 1980, Underwood \& Jernakoff 1981). The limpet Cellana tramoserica was able to limit the upward extension of a low-shore algal bed while the lower intertidal distribution of $C$. tramoserica was limited by the abundance of macroalgae. At higher levels on the shore algal propagules settled and grew slowly and C. tramoserica was able to graze these propagules effectively. At lower levels, however, algae settled and grew faster than the grazing rate of the limpet. C. tramoserica was unable to graze these macroalgae and rapidly starved to death

The small acmaeid limpet Patelloida latistrigata Angas is found within the barnacle zone at higher levels on the shore (Creese 1982, Underwood et al. 1983). In some localized places clumps of macroalgae surround $P$. latistrigata. These limpets do not starve to

\footnotetext{
- Present address: CSIRO Marine Laboratories, P.O. Box 20, North Beach 6020, Western Australia
}

death like Cellana tramoserica. They usually have a small clearing around their shells where they can graze microalgae although it is not known if the limpets also eat macroalgae.

In previous studies (Jernakoff 1983a, b) grazing by Patelloida latistrigata on algal abundance was estimated as percentage cover, because culturing and counting spores (Hruby \& Norton 1979) or counting microscopic propagules in the field (Kennelly \& Underwood 1984) was logistically impossible on the temporal and spatial scales of these investigations. The plants were small turfing forms (Jernakoff 1983b) and it was, therefore, not possible to count individual germlings or plants (Gunnill 1980).

In this paper I extend the study of the effects of 1 species of herbivorous limpet on the algal assemblage. In addition, I determine the influence of algae on these grazers. I examine whether (a) Petelloida latistrigata is an obligate grazer of microalgae; (b) grazing by $P$. latistrigata removes all algae from the substratum or whether microscopic forms are resistant to herbivory; (c) the dominance of ephemeral green algae in areas where grazers are excluded (Jernakoff 1983a, b) is due to the availability of propagules or some interaction among different types of germlings that occurs before plants are able to be counted in the field by percentage cover. 


\section{MATERIALS AND METHODS}

Study sites were on intertidal sandstone platforms in the Cape Banks Scientific Marine Research Area, Botany Bay, New South Wales (Australia) at a tidal height of 0.4 to $1.6 \mathrm{~m}$ above Indian Low Water Spring tidal level (datum) for Sydney, A more detailed description of these areas can be found in Jernakoff (1983a).

In some experiments cages were used to include or exclude Patelloida latistrigata. These cages were made of fine stainless steel fly-mesh and were $10 \times 10 \mathrm{~cm}$ and $3 \mathrm{~cm}$ high. They were fastened to the substratum by stainless steel screws into rawl-plugs. Gaps between the bottom of the cage and the substratum were filled with a silicon sealant (Selleys, Australia) to prevent limpets moving into or out of experimental areas. The fine mesh required for these cages in known to enhance algal recruitment (Jernakoff 1983a) but was necessary to restrict the movement of these small limpets (maximum shell length $10 \mathrm{~mm}$ ).

Limpets transferred to experimental areas were placed on the substratum and sprinkled with water to ensure that they reattached to the rock and would not desiccate nor be immediately washed away by waves. When Patelloida latistrigata were placed in macroalgal beds, an area the size of each limpet's shell was scraped back to bare rock and the limpet placed on the clearing and then sprinkled with water. When necessary, the shells were marked with a non-toxic marine paint (Mirotone Pty. Ltd., Sydney).

Biomass of Patelloida latistrigata was measured as shell-free dry weight $\left(60^{\circ} \mathrm{C}\right.$ for $\left.2 \mathrm{~d}\right)$. Limpets required for gut analyses were immediately killed in $7 \%$ formalin to stop further digestion of algae. They were then taken to the laboratory and dissected, and samples of food from the intestine could be collected with a pipette and smeared onto a microscope slide. The amount of algal tissue (percent covering the field of view from a microscope eye-piece grid) was recorded from 5 samples from the intestine of each limpet. Sampling other areas of the gut was unreliable because the adult limpets were small (average shell length $10 \mathrm{~mm}$ ). Any tissue that appeared to be of animal origin (e.g. from the walls of the ailamentary canal or digestive gland) was not counted.

Chips of rock taken from experimental plots were taken to the laboratory in moist plastic bags, placed in crystal dishes and covered with filtered seawater to culture the algal propagules on the rock for $6 \mathrm{~d}$. Algae were counted under a microscope with an eye-piece grid that covered an area of $5 \times 5 \mathrm{~mm}$ at a magnification of $\times 20$, and measured using a graduated eyepiece scale.

A number of different experiments were done during the study. The rationale and design of each experiment is therefore presented with the results.

\section{EXPERIMENTS AND RESULTS}

\section{Effect of grazing on algal propagules}

Spatial and short-term temporal variations in the effects of grazing and tidal height on algal recruitment were examined at 2 study sites. At each site, 4 cages were attached in the lower third of the barnacle zone and 4 cages were fixed two-thirds of the way up the zone. At each height, 2 of the 4 cages excluded grazers and the other 2 enclosed a natural density of Patelloida latistrigata ( 8 individuals). Two chips of rock from each cage were cultured in the laboratory at 2 and at $4 \mathrm{wk}$ after the start of the experiment.

Nine types of algae (excluding diatoms) were recorded in the experimental areas (Table 1). The size of algae ranged from $0.005 \mathrm{~mm}$ (e.g. Nostoc sp.) basal diameter to $1 \mathrm{~mm}$ for some colonies of algae (e.g. Aphanothece pallida). The number of individuals ranged from 1 to hundreds. Data collected consisted of either the number of individuals and their average basal diameter or the number of colonies and the mean diameter of the colony. These data were converted to a percentage of the total field of view $\left(25 \mathrm{~mm}^{2}\right)$ assuming that the algal colonies or basal section of individual algae were circular. Thus an absolute measure of the area of substratum covered by algae took into account different sizes, densities and types of plants. A single analysis of variance of all factors (sites, heights, grazers, times, cages, chips) would be unwieldy and the higher order interaction terms if significant, would be confusing. Analyses were, therefore, done for each particular site and time.

Patelloida latistrigata ate virtually all of the algal propagules that settled at both heights at each site and time (Fig. 1). In ungrazed treatments at each site, there was initially a lot of variability in the amount of algae among rock chips within cages. At the next sampling, the level of significant patchiness was at a larger scale - among cages (analyses of variance, $P<0.05$ ).

At first, the amount of algae at both heights was similar but at the next sampling time there were significantly more algae at lower levels on the shore (analyses of variance and S.N.K. tests, $P<0.05$; Fig. 1).

Between the first and second samplings there was a storm that damaged the cages at Site 2 thus allowing limpets to migrate into the ungrazed treatments and consume algae (although there were still significantly more algae in the ungrazed treatment). The amount of algae in ungrazed areas was, nevertheless, less than 
Table 1. Algal groups recorded in sampling

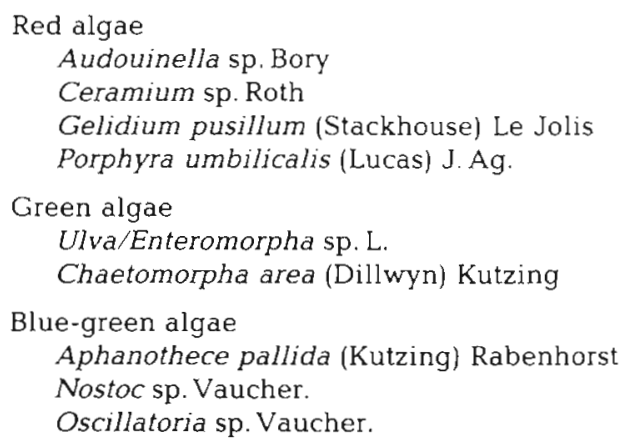

that found in the first samples (analyses of variance, $P$ $<0.05$ and S.N.K. tests; Fig. 1).

Not all algae showed the same trends. The abundance of some algae differed between sites (Table 2). In addition, some types were more abundant at the higher level (e.g. Aphanothece pallida and Oscillatoria sp.) while others (e.g. Audouniella sp.and Ulva sp.) were more abundant lower on the shore. Some algae were present only at the first time of sampling (e.g. Nostoc sp.) while others (e.g. Chaetomorpha area) were more abundant at the second time (Table 2). Two algae, Ceramium sp. and Gelidium pusillum only occurred in very small amounts at Site 1 at the lower height and at the second sampling time.

\section{Interactions of Patelloida latistrigata with established algae}

While Patelloida latistrigata could graze away algal propagules, the limpets were sometimes observed to be in areas completely enclosed by macroalgae. They were usually surrounded by an area of about $5 \mathrm{~mm}$ around their shells that was devoid of all plants, particularly in areas of Gelidium pusillum.

The ability pf Patelloida latistrigata to feed and survive when surrounded by macroalgae was investigated by placing the limpets into macroalgal beds. Ten adult $P$. latistrigata feeding on bare rock were marked and placed in clearings (the size of their shell) in each of three algal beds: Ulva sp., Aphanothece pallida and Gelidium pusillum. A fourth treatment, limpets placed on bare rock, was included as a control for the transplantation. The size of clearing amongst algae and number of $P$. latistrigata remaining in the areas were recorded for $53 \mathrm{~d}$.

The clearings within algal beds did not become larger during the experiment. In addition, limpets moved away from some of their macroalgal surroundings. At the end of the experiment, there were 8 out of the original 10 limpets in the control area plus a ninth limpet which was found $1 \mathrm{~m}$ away. There were 2 limpets remaining amongst Ulva sp., 3 amongst Aphanothece pallida and 5 amongst Gelidium pusillum. The results of the analyses were consistent by $26 \mathrm{~d}$; significantly more Patelloida latistrigata disappeared from areas of Ulva sp. and A. pallida, compared with control areas. There was no significant difference

\section{SITE 2}

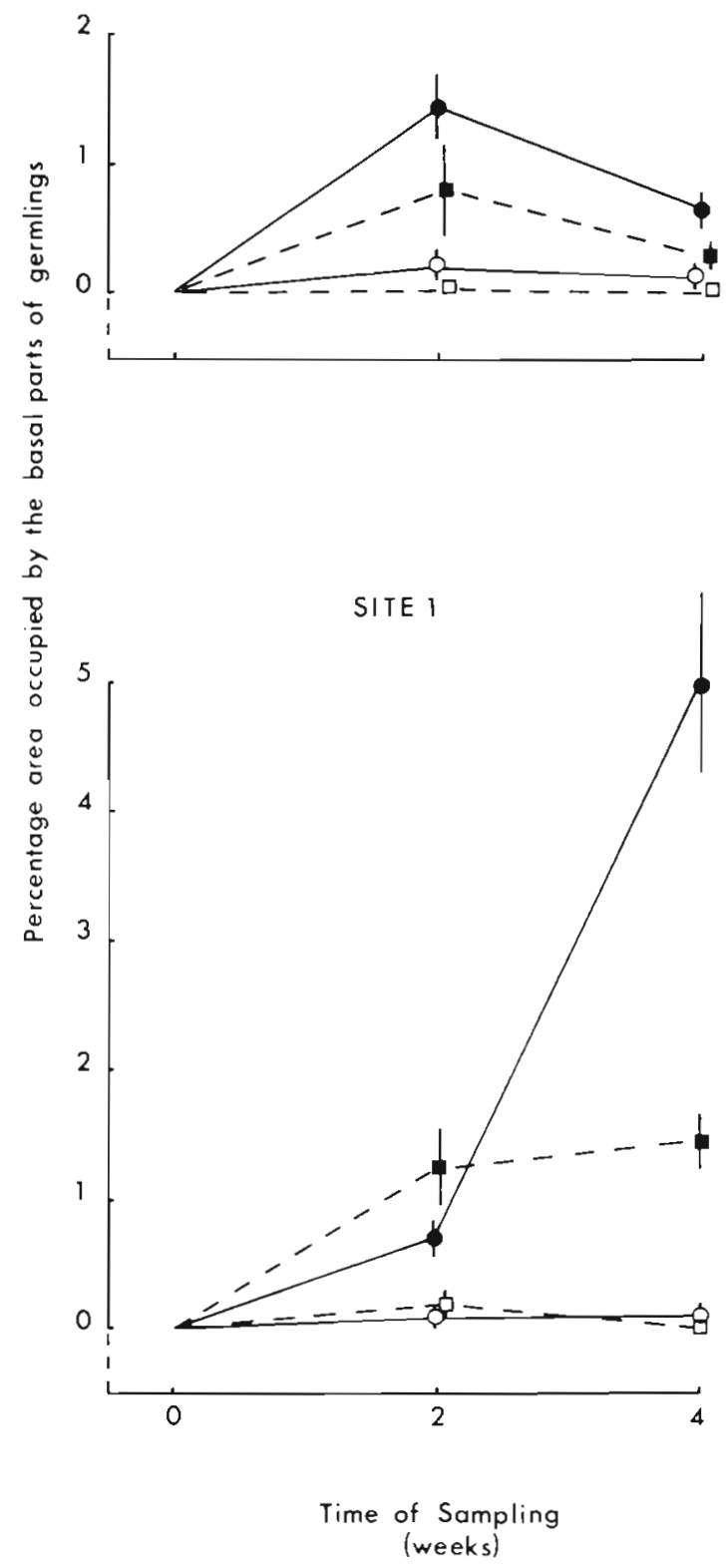

Fig. 1. Percentage area occupied by the basal parts of all germlings. Time $0=14 \mathrm{Mar} 83$; Time $1=25 \mathrm{Mar} 83$; Time 2 $=12 \mathrm{Apr} 83$. Lower height without Patelloida latistrigata; $O$ lower height with $P$. latistrigata; Middle height without $P$. latistrigata; $\square$ Middle height with $P$. latistrigata. Vertical bars standard errors $(n=20)$ 
Table 2. Mean cover of algae ( \pm SE) multiplied by 100 for Sites 1 and 2 at the lower and middle levels. Algae that occurred in very small amounts (e.g. Gelidium pusillum) or not at all (e.g. Aphanothece pallida at Site 2) omitted

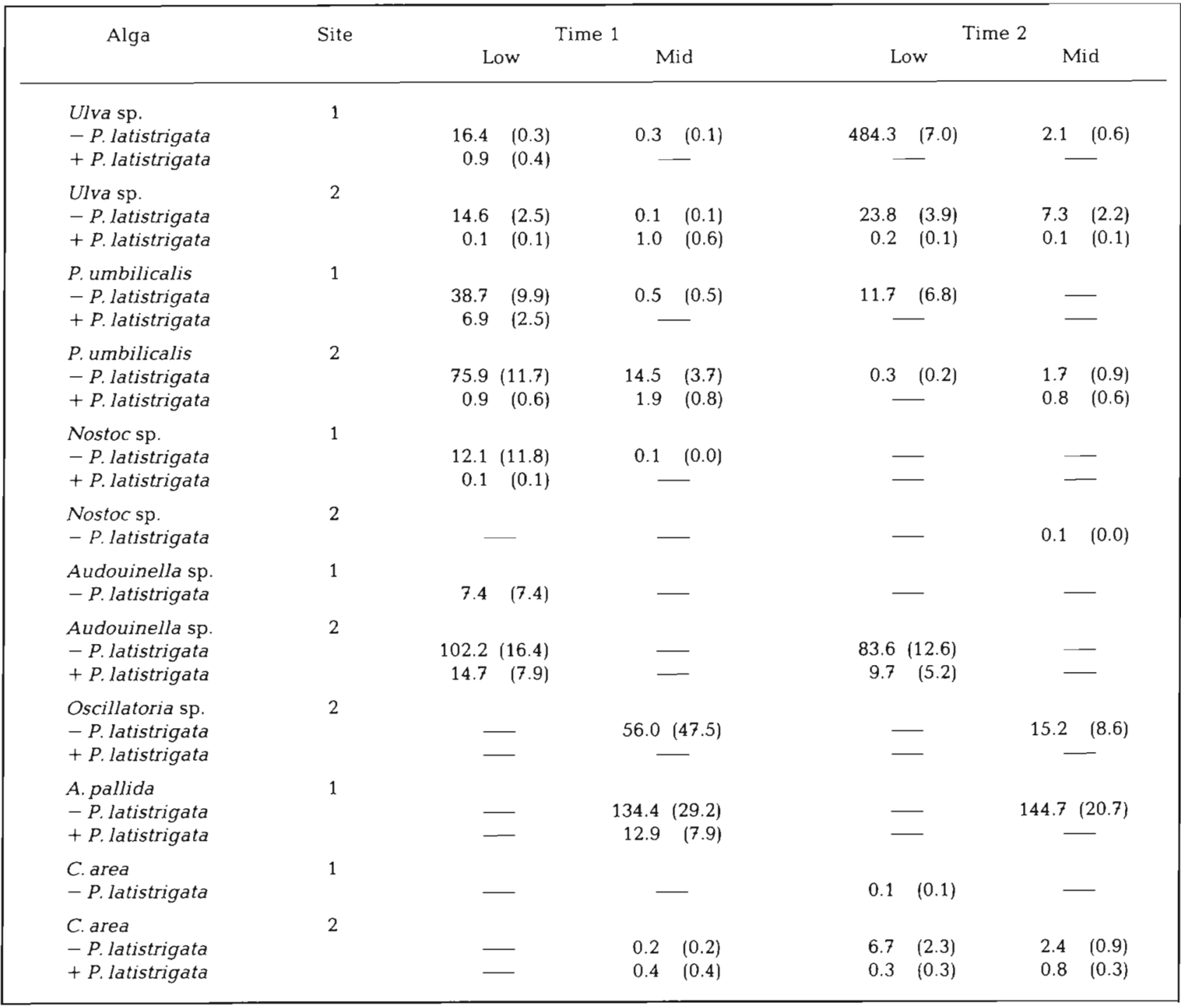

in the proportions of limpets remaining in areas with $G$. pusillum and in control areas (Fisher's Exact test, $P$ $>0.05$ ).

Many of the Patelloida latistrigata that disappeared from the algal treatments could not be found anywhere. It was possible that the missing limpets were eaten by predators, or that limpets starved to death or were washed away by waves when they tried to climb over the algae. A subsequent experiment was set up where cages were used to exclude any potential predators and also to ensure that limpets were not washed away by wave-action.

Twenty-eight limpets (of similar size; $10 \mathrm{~mm}$ ) were caged at their normal density (8 limpets $100 \mathrm{~cm}^{-2}$ ) in clearings (the size of their shell) in areas of Ulva sp., Aphanothece pallida or Gelidium pusillum. A control group was caged on bare rock. At each sampling, 4 limpets from each treatment and 4 uncaged limpets grazing on bare rock were taken to the laboratory, dried and weighed. The original density of limpets was maintained with marked replacements that were not weighed. Limpets were collected at the start and after 11,40 and $73 \mathrm{~d}$, until algal growth appeared in the control cages. At the end of the experiment, 4 of the original limpets from each treatment, plus four Patelloida latistrigata living naturally on bare rock that were not caged, were collected for gut analyses.

At the end of the experiment, the cleared spaces around Patelloida latistrigata in the macroalgae were only marginally larger (less than $3 \mathrm{~mm}$ clear around each limpet) than when the experiment was set up. This increase in size within the algal patch could have 
been due to a reaction on the surrounding algae to being damaged by clearing, or a response to the movements of the limpets, or due to grazing. There was no significant difference in the weights of $P$. latistrigata placed in clearings amongst algae or the caged, and uncaged control limpets at any stage of the experiment (analyses of variance; $P>0.05$ ).

The guts of the limpets contained macroalgae, sand and broken up tissue, presumably of macroalgal origin, as well as unidentifiable material (see Table 3), and were similar to those described by Creese (1978). There was significantly more macroalgal material sampled from the intestine of Patelloida latistrigata amongst Aphanothece pallida and Gelidium pusillum than in other treatments. The caged and uncaged control treatments and the UIva sp. treatment all had similar quantities of tissue (Table 3 ).

While it appears that limpets can eat mature plants, they were never observed feeding actively on the plants. To examine whether the size of plant influenced the feeding ability of Patelloida latistrigata, limpets were exposed to different sizes of algae. Four sandstone plates $(8 \times 4 \mathrm{~cm})$ were placed on an isolated boulder that was kept free from grazers (Jernakoff 1983a). After $2 \mathrm{wk}$, a second set of plates was put out. By $4 \mathrm{wk}$, the first set of plates were covered with a visible layer of Ulva sp. and Enteromorphasp. and the second set of plates ( 2 wk old) were covered with a layer of diatoms. At this time, all the plates were taken back to the laboratory, placed in crystal dishes and covered with filtered seawater. $P$. latistrigata (shell length $8 \mathrm{~mm}$ ) were taken from areas with no visible macroalgae and placed on the plates on small cleared areas. After $2 \mathrm{wk}$, the zone of grazing and condition of limpets was noted and the faeces of these limpets were examined under a binocular dissecting microscope.

Patelloida latistrigata on the 2 wk old plates had faeces similar in appearance to those of control limpets collected from the shore. A clearly defined grazed area could be seen on the plate around each limpet. Limpets placed on the $4 \mathrm{wk}$ old plates had also cleared areas; these were smaller than those on the 2 wk old plates. $P$. latistrigata on the older plates (with larger algae) appeared only to feed by rotating on their home site. While some of the faeces of these limpets were similar to those from individuals on the younger plates, other faeces were dramatically different. Some faeces contained blue-green algae and germlings of ulvoid algae complete with chlorophyll (Fig. 2). These plants had passed through the gut of the limpets with little visible damage; the chloroplasts and cells appeared to be intact. Some of these faeces were transferred to clean sandstone plates, covered with filtered seawater, and examined twice per week. After 2 wk, 2 of 4 original germlings in the faeces had reattached to the rock. All 4 plants appeared to be alive (as evidenced by their green chloroplasts). They were, however, covered by a heavy epiphytic growth of blue-green algae and did not look very healthy when compared to ungrazed plants. On plates with established green algae, only very small germlings were ever eaten.

\section{DISCUSSION}

\section{Interactions between Patelloida latistrigata and propagules}

Patelloida latistrigata ate virtually all algae that settled. In a previous study the cover of the blue-green alga Aphanothece pallida was not affected by the presence of grazers (Jernakoff 1983a). This differs from the present study where the cover of the alga was reduced by $P$. latistrigata. Later stages of the alga may have chemicals repellent to the grazers or there may be a size-related escape from grazing (reviews by Lubchenco \& Gaines 1981, Hawkins \& Hartnoll 1983). The presence of other algae in ungrazed areas has not, however, been previously recorded. Many of these algae were never observed during the early stages of recruitment in the field (Jernakoff 1983a, b), because of their very small size (many were only visible under a microscope) and the rapid overgrowth by ulvoids which would have excluded other algae. Thus, previous investigations where algal abundance was mea-

Table 3. Percentage cover of material in smears from intestine of limpets. Means ( \pm SE) based on 20 readings (from 5 fields of view from each of 4 limpets)

\begin{tabular}{llrrr|}
\hline \multicolumn{1}{|c}{ Algal bed } & Microalgae & Macroalgal tissue & Sand & $\begin{array}{c}\text { Unidentifiable } \\
\text { material }\end{array}$ \\
\hline G.pusillum & & & & \\
A.pallida & $0.3(0.2)$ & $24.9(3.8)$ & $0.1(0.1)$ & $0.7(0.4)$ \\
Ulva sp. & $0.5(0.2)$ & $18.9(2.5)$ & $0.8(0.2)$ & $1.3(0.5)$ \\
Caged control (bare rock) & $1.0(0.4)$ & $3.6(0.9)$ & $0.1(0.1)$ & $0.7(0.4)$ \\
Uncaged control (bare rock) & $0.8(1.4)$ & $9.3(1.4)$ & $0.1(0.1)$ & $0.4(0.3)$ \\
\end{tabular}



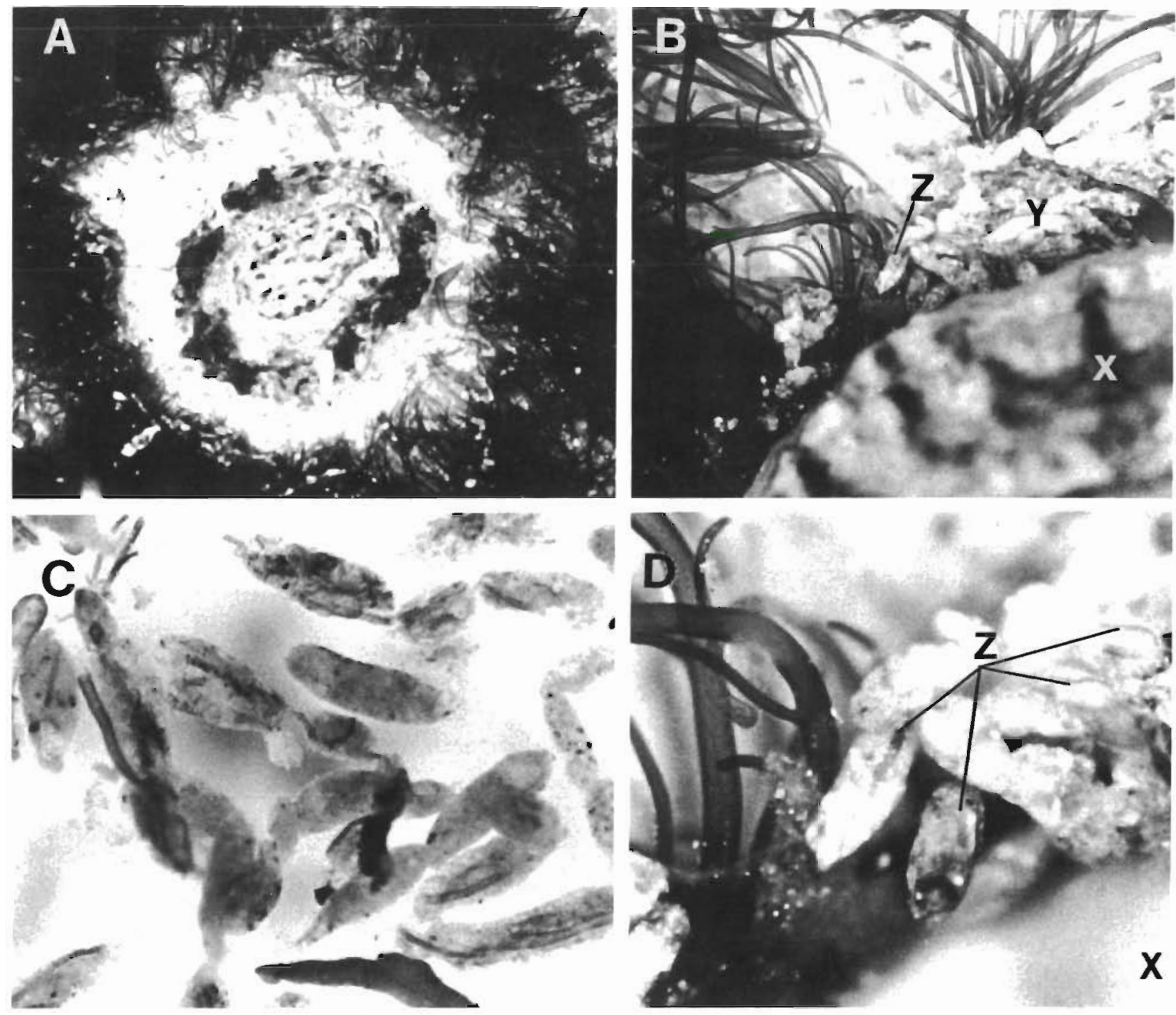

Fig. 2. Patelloida latistrigata. Effect of grazing on macroalgae. (A) Grazing scar amongst Ulva sp. and Enteromorpha sp.; $\times 5$ magnification. (B) Faeces; X: limpet shell; Y: faeces; $Z$ : faeces containing algae; $\times 17$. (C) Collection of limpet faeces containing algae; $\times 42$; (D) Enlarged section of $B_{i} \times 53$

sured by percentage cover estimated in the field may have underestimated total algal diversity because species were either already overgrown by ephemeral algae or too small to be seen.

Greater numbers and amounts of algae recruited at lower levels in the zone although some blue-green algae (Aphanothece pallida and Oscillatoriasp.) were more abundant at higher levels. The lower levels remained submersed for longer periods of time and thus propagules settling at higher levels would suffer greater mortality from desiccation (Mathieson 1982). This is unlikely in the present study. The cages were made of a fine mesh that greatly reduced desiccation and the areas were continuously subjected to low to moderate wave-action. The rock under the cages at both levels remained moist during low tide due to splash from wave-action, decreased amounts of sunlight and reduced exposure to wind (allowing greater humidity). An alternative but untested hypothesis is that more propagules settled at lower levels because these levels were covered by water for longer periods of time. While this may be true for some algal species, it was certainly not true for Aphanothece pallida nor Oscillatoria sp. Also, it is unlikely that these bluegreen algae were competitively excluded from lower levels (e.g. Lubchenco 1980, Schonbeck \& Norton 1980, Kastendiek 1982) because bare rock was always readily available on which to settle (Table 2 ) and no overgrowth by other species occurred in such a short time span (2 to $4 \mathrm{wk}$ ). 


\section{Interactions between Patelloida latistrigata and adult} plants

The disappearance of the limpet from patches of different macroalgae varied, suggesting that the limpet may prefer some macroalgal species over others. Laboratory studies designed to distinguish feeding preference of the limpet were, unfortunately, unsuccessful.

The reason why more Patelloida latistrigata disappeared from clearings in beds of Aphanothece pallida and Ulva sp. compared with Gelidium pusillum or control areas is not known. Predation was unlikely because $90 \%$ of control individuals were found within or outside experimental plots and no predators were observed near or in algal beds. Probably more $P$. latistrigata attempted to move away from beds of $A$. pallida and Ulva sp. and were washed away by waves as they attempted to climb over the algae. G. pusillum had the least effect on the movement of $P$. latistrigata out of the 3 types of algal beds.

When Patelloida latistrigata were caged in clearings in these algae so that they could not move away, there was no mortality nor significant change in weight of grazers that were kept amongst algae compared with caged and uncaged control animals. Thus, Patelloida latistrigata caged in algae were either eating macroalgae or eating microalgae growing on the macroalgae or in the cleared spaces around limpets. Analyses of gut contents confirmed that $P$. latistrigata had eaten macroalgae (Table 3). Although macroalgal tissue was found in the guts of control individuals (control areas were never completely bare of macroalgae) significantly more macroalgal tissue was found in limpets that had been caged on Aphanothece pallida and Gelidium pusillum. These results support the findings of Creese (1978). Limpets with the least amount of macroalgal tissue in the gut were from beds of Ulva sp., but no explanation is offered for this. Ephemeral green algae are definitely eaten in great numbers as propagules (Table 2; Jernakoff 1983a, b and numerous other studies; see reviews by Lubchenco \& Gaines 1981, Hawkins \& Hartnoll 1983). Where grazers are experimentally excluded, Ulvoids make up the majority of algae present (Jernakoff 1983a, b) and thus spores of these plants definitely form a large part of the diet of $P$. latistrigata.

While Patelloida latistrigata placed on sandstone plates could easily graze small (2 wk old) ulvoid sporelings, larger and older ( $4 \mathrm{wk}$ old) plants were less easily eaten. The limpets did not expand their cleared spaces and grazed by rotating on their scar. The appearance of germlings with apparently intact chloroplasts and blue-green algae in some of the faeces demonstrated that whole plants were being ingested with little digestion taking place. This phenomenon of herbivores being unable to digest plant material is widespread (e.g. Porter 1973, McKey 1975, Nicotri 1977, Lobel 1980, Santelices et al. 1983).

The inability of Patelloida latistrigata to digest small germlings (Fig. 2) may be due to their docoglossan radula that is used for rasping the substratum. Germlings of this size are ingested with apparently little mechanical damage and cannot be efficiently digested. Rasping larger plants may break down plant tissue and cell contents allowing $P$. latistrigata to eat macroalgae when necessary.

\section{CONCLUSIONS}

Throughout the barnacle zone, juvenile and adult grazers and germlings and established plants co-occur and may interact. The outcome of interactions between juvenile Patelloida latistrigata and germlings may vary, depending on physical conditions and the presence of adult limpets. The most significant type of interaction is between adult grazers and algal propagules, where bare space is maintained by grazing. The grazers are efficient at finding and consuming propagules, and rough topography or crevices amongst barnacles provide germlings with little shelter from being grazed (Jernakoff 1983a, b). Lubchenco (1983) found that ephemeral algae were readily grazed by Littorina littorea but Fucus growing amongst barnacles escaped (see also Lubchenco \& Menge 1978). The efficiency of the refuge was, however, a function of the density of grazers. Grazing by L. littorea on Fucus is probably similar to that by $P$. latistrigata on mature ephemeral algae in the present study. While $P$. latistrigata are able to eat macroalgal plants, they prefer microalgae and germlings and will, if possible, generally move away from macroalgal areas.

Creese (1982) demonstrated that, when transplanted into low shore algal beds, Patelloida latistrigata were overgrown by adult plants and killed. I have never observed this in the barnacle zone. The intensity of settlement and rate of growth of algae within the barnacle zone is rarely as great as the grazing abilities of the limpet hence adult macroalgae are usually found in small clumps.

The reason why Patelloida latistrigata is able to eat macroalgae, while its dominant competitor Cellana tramoserica (Creese 1982, Underwood et al. 1983) that has the same type of radula is unable to do so, is unknown. Whatever the reason, it is evident that $P$. latistrigata is not an obligate grazer of microalgae although its behaviour is influenced by the presence of mature plants. 
Acknowledgements. This research was funded by a University of Sydney Research grant and forms part of my Ph. D. dissertation. The help of my supervisor A. J. Underwood is gratefully acknowledged. Helpful comments on this paper were provided by A. J. Underwood, R. G. Creese and K. A. McGuinness.

\section{LTERATURE CITED}

Creese, R. G. (1978). Ecology and reproductive biology of intertidal limpets. Ph. D. thesis, University of Sydney

Creese, R. G. (1982). The distribution and abundance of the limpet Patelloida latistrigata, and its interaction with barnacles. Oecologia 52: 85-96

Gunnill, F. C. (1980). Recruitment and standing stocks in populations of one green algae and five brown algae in the intertidal zone near La Jolla, California during 1973-1977. Mar. Ecol. Prog. Ser. 3: 231-244

Hawkins, S. J., Hartnoll, R. G. (1983). Grazing of intertidal algae by marine invertebrates. Oceanogr. mar. Biol. A. Rev. 21: 195-282

Hruby, T., Norton, T. A. (1979). Algal colonization on rocky shores in the Firth of Clyde. J. Ecol. 67: 65-77

Jernakoff, P. (1983a). Factors affecting the recruitment of algae in a midshore region dominated by barnacles. J. exp. mar. Biol. Ecol. 66: 17-31

Jernakoff, P. (1983b). Interactions among algimals and algae in an intertidal zone dominated by barnacles. Ph. D. thesis, University of Sydney, Australia

Kastendiek, J. (1982). Competitor mediated coexistence: interactions among three species of benthic macroalgae. J. exp. mar. Biol. Ecol. 62: 201-210

Kennelly, S. K., Underwood, A. J. (1984). Underwater microscopic sampling of a sublittoral kelp community. J. exp. mar. Biol. Ecol. 76: 67-78

Lobel, P. S. (1980). Herbivory by damselfishes and their role in coral reef community ecology. Bull. mar. Sci. 30: 273-289

Lubchenco, J. (1980). Algal zonation in the New England rocky intertidal community: an experimental analysis. Ecology 61: 333-344
Lubchenco, J. (1983). Littorina and Fucus: Effects of herbivores, substratum heterogeneity, and plant escapes during succession. Ecology 64: 1116-1123

Lubchenco, J, Menge, B. A. (1978). Community development and persistence in a rocky intertidal zone. Ecol. Monogr. 48: $67-94$

Lubchenco, J., Gaines, S. D. (1981). A unified approach to marine plant-herbivore interactions. I. Populations and communities. Ann. Rev. Ecol. Syst. 12: 405-437

Mathieson, A. C. (1982). Physiological ecology of the brown alga Phaestrophion irregulare Setchel et Gardner: 1. Juvenile plants. Botanica mar. 25: 87-91

McKey, D. (1975). The ecology of coevolved seed dispersal systemı. In: Gibert, L. E., Raven, P. H. (ed.) Coevolution of plants and animals. University of Texas Press, Austin, 159-191

Nicotri, M. E. (1977). Grazing effects on four marine intertidal herbivores on the microflora. Ecology 58: 1020-1032

Porter, K. G. (1973). Selective grazing and differential digestion of algae by zooplankton. Nature, Lond. 244: 179-180

Santelices, B., Correa, J., Avila, M. (1983). Benthic algal spores surviving digestion by sea urchins. J. exp. mar. Biol. Ecol. 70: 263-269

Schonbeck, M. W., Norton, T. A. (1980). The effects on intertidal fucoid algae of exposure to air under various conditions. Botanica mar. 23: 141-148

Underwood, A. J. (1980). The effects of grazing by gastropods and physical factors on the upper limits of distribution of intertidal macroalgae. Oecologia 46: 201-213

Underwood, A. J., Denley, E. J., Moran, M. J. (1983). Experimental analyses of the structure and dynamics of midshore rocky intertidal communities in New South Wales. Oecologia 56: 202-219

Underwood, A. J., Jernakoff, P. (1981). Effects of interactions between algae and grazing gastropods on the structure of a low shore intertidal algal community. Oecologia 48: 221-233

Underwood, A. J., Jernakoff, P. (1984). Effects of tidal height, wave-exposure, seasonality and rockpools on grazing and the distribution of intertidal macroalgae in New South Wales. J. exp. mar. Biol. Ecol. 75: 71-96 